\title{
Descolonização e resistência: a UNILAB e a formação de professores de História para o Brasil e a África
}

\author{
Decolonization and resistance: UNILAB and the training of history teachers \\ for Brazil and Africa
}

Robério Américo do Carmo Souza*

Universidade da Integração Internacional da Lusofonia Afro-Brasileira (UNILAB), Acarape, CE, Brasil

\begin{abstract}
RESUMO: Como conceber e pôr em prática um curso que atenda as expectativas e necessidades para a formação de professores para atuar no Brasil e na África Lusófona? É essa a questão que orienta as reflexões deste artigo. Nele, tomo como objeto a elaboração e a execução do Projeto Pedagógico Curricular (PPC) do Curso de Licenciatura em História da Universidade da Integração Internacional da Lusofonia AfroBrasileira (UNILAB), refletindo sobre os desafios e as perspectivas de uma formação que visa a preparar professores para atuar no Brasil, em Angola, Cabo Verde, Guiné Bissau, Moçambique e Angola. Seu objetivo é problematizar a formação pensada no $\mathrm{PPC}$ e como esta foi posta em prática nos primeiros anos de existência do curso. A análise é dividida em dois eixos distintos e complementares, o primeiro deles aborda a formação histórica, refletindo sobre o esforço em construir e executar o currículo com base em princípios de recusa às narrativas eurocêntricas e de busca por uma abordagem descolonizada da História. O segundo eixo aborda a formação pedagógica, dedicando-se a pensar sobre os conteúdos obrigatórios da área da Pedagogia para os cursos de licenciatura e a execução do estágio supervisionado, analisando como o currículo proposto dialoga com a legislação brasileira para área de Formação de Professores, e em que medida essa legislação cria entraves à proposta formativa e aos objetivos o curso.
\end{abstract}

PALAVRAS-CHAVE: História. Formação de professores. Brasil-África.

ABSTRACT: How to design and implement a course that meets the expectations and needs for the training of teachers to work in Brazil and in Lusophone Africa? This is the question that guides the reflections of this article. In it, I take as object the elaboration and execution of the Curricular Pedagogical Project (CPP) of the Degree in History of the University of International Integration of Afro-Brazilian Lusophony (UNILAB), reflecting on the

\footnotetext{
* Professor da Universidade da Integração Internacional da Lusofonia Afro-Brasileira (UNILAB). Doutor em História pela Universidade Federal Fluminense (UFF). E-mail: americosouza@unilab.edu.br. https://orcid.org/0000-0002-1206-5085.
} 
challenges and perspectives of a training aimed at preparing teachers to operate in Brazil, Angola, Cape Verde, Guinea Bissau, Mozambique and Angola. Its objective is to problematize the training thought in the CPP and how it has been put into practice in the first years of existence of the course. The analysis is divided into two distinct and complementary axes, the first of which addresses historical formation, reflecting on the effort to construct and execute the curriculum based on principles of refusal to Eurocentric narratives and search for a decolonized approach to History. The second axis deals with pedagogical training, focusing on the compulsory contents of the Pedagogy area for undergraduate courses and supervised internship, analyzing how the proposed curriculum dialogues with the Brazilian legislation for the area of Teacher Training, and to what extent this legislation creates obstacles to the training proposal and the objectives of the course.

KEYWORDS: History. Teacher training. Brazil-Africa.

\section{Introdução}

Ao longo dos treze anos em que esteve no comando do Governo Federal, o Partido dos Trabalhadores promoveu uma reorientação da política internacional brasileira, pondo mais ênfase no fomento de acordos e parcerias estratégicas com países em desenvolvimento e organizaçóes internacionais que os congregam. São bem conhecidas as ações que foram efetivadas no campo da economia, buscando incremento para o comércio, a produção de energia e a produção industrial. No entanto, também a educação superior foi esteio deste reordenamento.

Com base nos princípios da cooperação solidária e da integração regional, princípios que norteiam o estabelecimento de acordos de reciprocidade, implementaram-se políticas públicas que favoreceram intercâmbios prioritários com países da América Latina e da África Lusófona, pautados no estímulo à produção e à troca de fazeres e saberes para formação universitária, em um movimento compreendido por Fabio Betioli Contel e Manolita Correia Lima (2011) como sendo de favorecimento de relações acadêmicas Sul-Sul, menos hierarquizadas que os tradicionais intercâmbios Norte-Sul.

Fomentar a construção de um intercâmbio Sul-Sul no campo da educação superior implica, entre outras coisas, um repensar de paradigmas e perspectivas da própria construção do conhecimento, posto que há no campo acadêmico localizado abaixo da linha do Equador uma hegemonia epistemológica europeia. É preciso postular um modelo educacional de resistência que potencialize a construção e aplicação de uma “epistemologia do Sul”, como propôs J. A. Nunes.

O projeto de uma epistemologia do sul é indissociável de um contexto histórico em que emergem com particular visibilidade e vigor novos atores históricos no Sul global, sujeitos coletivos de outras formas de saber e de conhecimento que, a partir do cânone epistemológico ocidental, foram ignorados, silenciados, marginalizados, desqualificados ou simplesmente eliminados, vítimas de epistemicídios tantas vezes perpetrados em nome da razão, das luzes e do Progresso. (NUNES, 2010, p. 280)

Como forma de sistematizar e institucionalizar esta política de integração educacional SulSul, foram criadas duas universidades federais com foco na internacionalização cooperativa, a Universidade Federal da Integração Latino-Americana (UNILA), com foco na América Latina e no Caribe, e a Universidade da Integração Internacional da Lusofonia A fro-Brasileira (UNILAB), 
voltada para os países das Comunidades de Países de Língua Portuguesa (CPLP), com especial ênfase nas nações africanas.

Importa também destacar que a criação destas instituições se insere dentro do que Nilma Lino Gomes e Sofia Lecher chamaram de "quarto ciclo expansionista da educação superior”, que elas localizam como ligadas:

[...] ao período ocorrido depois da estabilização econômica do país, quando iniciativas diversas de inclusão social e políticas afirmativas foram estimuladas, propiciando uma melhoria da distribuição de renda, o que tem sido associado à emergência de uma nova classe média. Neste contexto, tem se destacado não apenas o crescimento do consumo de bens econômicos, como também de bens culturais. A ampliação do acesso à educação superior é parte deste movimento, onde a aspiração pela universidade passa a integrar o imaginário de famílias antes pertencentes aos setores mais pobres da população. (GOMES; LECHER, 2013, p. 78)

Criada em 2010 e implantada em 2011, a UNILAB estabeleceu a formação de professores para a educação básica como um dos seus eixos de formação. Em seu oitavo ano de funcionamento, a universidade possui hoje em dia doze cursos de licenciatura, oito que funcionam nos campi da UNILAB no Ceará, em Palmares, nas cidades de Acarape e Liberdade, na cidade de Redenção (Letras, História, Sociologia, Pedagogia, Matemática, Física, Química, Biologia), e quatro que funcionam no Campus dos Malês da UNILAB, localizado na cidade de São Francisco do Conde, na Bahia (Letras, História, Ciências Sociais e Pedagogia).

Até então inédita no meio acadêmico brasileiro, a formação sistemática de professores para atuarem em pelo menos sete países diferentes mostrou-se um desafio tão complexo quanto instigante, que tem exigido do corpo docente da UNILAB um singular esforço de pesquisa e de inventividade, na perspectiva de conceber formações capazes de contemplar realidades educacionais tão plurais. Este artigo propõe-se a compartilhar reflexões, ainda em estágio embrionário, sobre a trajetória do Curso de Licenciatura em História, sediado no Campus dos Palmares, município de Acarape, estado do Ceará, na busca pelos caminhos formativos de um professor-historiador internacional, problematizando a elaboração, reforma e aplicação da sua proposta curricular.

\section{Perseguindo uma formação invulgar: a concepção de um currículo descolonizador}

O Curso de Licenciatura em História do Instituto de Humanidades e Letras da UNILAB foi idealizado como um curso de segundo ciclo (terminalidade) do Bacharelado em Humanidades, curso propedêutico que se propõe a dar uma formação interdisciplinar de dois anos, como preparação para o ingresso em cursos de formação terminativa de caráter profissionalizante, com duração de três anos. No caso do Bacharelado em Humanidades da UNILAB-CE, os estudantes que o concluem têm quatro opções de formação em segundo ciclo: Pedagogia, Bacharelado em Antropologia, Licenciatura em Sociologia e, aquela que aqui nos interessa mais a miúde, a Licenciatura em História.

O curso de Licenciatura em História teve sua aprovação no Conselho Universitário em agosto de 2014 e começou a funcionar no segundo semestre de 2015. A sua formatação teve início em 
junho de 2013, quando foi constituída, pela Pró-Reitoria de Graduação e pela direção do Instituto de Humanidades e Letras, a primeira comissão para elaboração do Projeto Pedagógico Curricular (PPC) do curso'.

Ao longo dos seus dez meses de trabalho, a comissão sofreu algumas alterações em sua composição, tendo mantido como membros, do início até o final, os professores Dr. Fábio Baqueiro Figueiredo, Dr. Fernando Afonso Ferreira Junior, Dr. - Larissa Gabarra, Dr. José Weyne Sousa e Dr. Robério Américo do Carmo Souza.

Para além dos desafios inerentes à elaboração de qualquer PPC de um curso de graduação, tínhamos algumas peculiaridades que tornavam a tarefa ainda mais desafiadora. Entre elas, a já mencionada condição de ser um curso de segundo ciclo, com duração máxima de três anos e o regime diferenciado da UNILAB que, então, trabalhava com um calendário acadêmico trimestral. No entanto, o desafio maior, e por certo o mais instigante, residia na questão: como conceber um curso que atendesse as expectativas e necessidades de um corpo discente composto por estudantes brasileiros e estrangeiros, bem como respeitasse os parâmetros normativos do Ministério da Educação para reconhecimento do curso?

\section{(Re)Pensando a formação em História}

Como bem demonstram Norma Lúcia da Silva e Marieta de Morais Ferreira (2016), na década de 1970, estabeleceu-se no Brasil um modelo standard, para os cursos de licenciatura em História, dividido em quatro eixos básicos: História do Brasil, História Geral, Teoria da História e Metodologia do Ensino de História. Nas primeiras reunióes da comissão, ficou claro que esse modelo se mostrava inadequado para um curso internacional, alocado em uma universidade concebida sob a égide da integração Brasil-África.

Em nossos esforços para definição de parâmetros mais adequados aos propósitos educacionais da UNILAB foram de grande ajuda as reflexões de Enrique Dussel (2000, p. 32-33) sobre o que chamou de "paradigma eurocêntrico da modernidade", a partir do qual propóe uma descolonização do conhecimento, permitindo que se reconheça e se valorize o eixo asiático-afro-mediterrâneo do pensamento humano.

Sob a premissa de Dussel, a comissão, ao final de seu trabalho, elaborou um PPC que se pretendia descolonizado e descolonizador, e que também buscava avançar no trato pedagógico interdisciplinar da diversidade, da différence, da pluralidade cultural, de populaçóes migrantes e das relações de contato entre grupos variados. Além da formação de professores-pesquisadores antenados com grandes problemas contemporâneos, seu objetivo era o de engendrar uma ação teórico-prática que sistematizasse teoria com saber-fazer, associada à afirmação de valores e atitudes voltadas para a aprendizagem crítica do aluno (desenvolvendo as habilidades como o estímulo à imaginação, ao pensamento crítico, à capacidade de inovação e de tomar decisóes levando em consideração os princípios de convivência democrática e as diversidades de classe, racial, cultural, gênero, étnica, sexual, linguística, entre outras) e que acompanhem as transformações requeridas para o aperfeiçoamento do ensino de História e o bem comum da sociedade. 
Outra referência importante na elaboração do PPC foi Tomas Tadeu da Silva, em sua compreensão de que "[...] é através do vínculo entre conhecimento, identidade e poder que os temas da raça e da etnia ganham seu lugar no território curricular” (1999, p. 101).

Inspiradas em Dussel e Silva, foram concebidas as premissas que orientaram princípios curriculares do curso: a interculturalidade, a crítica ao eurocentrismo, a ênfase nas relações BrasilÁfrica e na cooperação Sul-Sul, a indissociabilidade entre o saber e o fazer, a prática de pesquisa articulada à prática de ensino, o compromisso com a democratização do ensino e com a produção do conhecimento, que podem ser evidenciadas na composição curricular do "Núcleo Obrigatório da Área de História” dos dois PPCs do Curso. O primeiro, com qual o curso é fundado, em 2014, (Quadro 1) e o segundo, de 2017, surgido a partir de alterações realizadas para adequá-lo ao novo regime da universidade, que passou a ser semestral e à exigência de curricularização da extensão, feita pelo Plano Nacional de Educação (Quadro 2).

Quadro 1 - Núcleo de disciplinas obrigatória PPC antigo

\begin{tabular}{|c|c|c|c|}
\hline CÓDIGO & DISCIPLINA & $\mathrm{CH}$ & Teo./PCC/Prat. \\
\hline & Antiguidade Africana e Médio-Oriental & $40 \mathrm{~h}$ & 3.1 .0 \\
\hline & A Construção da Abordagem Histórica & $40 \mathrm{~h}$ & 3.1 .0 \\
\hline & Europa Antiga e Medieval & $40 \mathrm{~h}$ & 3.1 .0 \\
\hline & História e Historiografia da Ásia & $40 \mathrm{~h}$ & 3.1 .0 \\
\hline & História e Historiografia da África & $40 \mathrm{~h}$ & 3.1 .0 \\
\hline & História e Historiografia da América & $40 \mathrm{~h}$ & 3.1 .0 \\
\hline & Historiografia I & $40 \mathrm{~h}$ & 3.1 .0 \\
\hline & Historiografia II & $40 \mathrm{~h}$ & 3.1 .0 \\
\hline & O Mundo Islâmico & $40 \mathrm{~h}$ & 3.1 .0 \\
\hline & A Expansão Europeia & $40 \mathrm{~h}$ & 3.1 .0 \\
\hline & As Revoluções Atlânticas & $40 \mathrm{~h}$ & 3.1 .0 \\
\hline & O Mundo Contemporâneo & $40 \mathrm{~h}$ & 3.1 .0 \\
\hline & O Mundo e a Guerra Fria & $40 \mathrm{~h}$ & 3.1 .0 \\
\hline & A América e a Dominação Ocidental & $40 \mathrm{~h}$ & 3.1 .0 \\
\hline & A Ásia e a Dominação Ocidental & $40 \mathrm{~h}$ & 3.1 .0 \\
\hline & A África e a Dominação Ocidental & $40 \mathrm{~h}$ & 3.1 .0 \\
\hline & Historiografia e o Mundo Colonial & $40 \mathrm{~h}$ & 3.1 .0 \\
\hline & Laboratório de Fontes e Métodos I & $80 \mathrm{~h}$ & 4.0 .2 \\
\hline & Laboratório de Fontes e Métodos II & $80 \mathrm{~h}$ & 2.2 .4 \\
\hline & Laboratório de Fontes e Métodos III & $80 \mathrm{~h}$ & 2.6.0 \\
\hline
\end{tabular}

Fonte: PPC do Curso de Licenciatura em História da UNILAB, 2014, p. 45 
Quadro 2 - Núcleo de disciplinas obrigatórias PPC atual

\begin{tabular}{|c|c|c|c|c|}
\hline $\begin{array}{c}\text { NÚCLEO OBRIGATÓRIO DA ÁREA DE } \\
\text { HISTÓRIA }\end{array}$ & $\begin{array}{l}\text { C.H. } \\
\text { TOTAL }\end{array}$ & Teórico & Extensão & PCC \\
\hline $\begin{array}{l}\text { Antiguidade Africana, Médio-Oriental e } \\
\text { Mediterrânea }\end{array}$ & $90 \mathrm{~h}$ & $60 \mathrm{~h}$ & $15 \mathrm{~h}$ & $15 \mathrm{~h}$ \\
\hline A Construção da Abordagem Histórica & $90 \mathrm{~h}$ & $60 \mathrm{~h}$ & $15 \mathrm{~h}$ & $15 \mathrm{~h}$ \\
\hline O Mundo Islâmico e o Medievo Europeu & $90 \mathrm{~h}$ & $60 \mathrm{~h}$ & $15 \mathrm{~h}$ & $15 \mathrm{~h}$ \\
\hline Historiografia & $90 \mathrm{~h}$ & $60 \mathrm{~h}$ & $15 \mathrm{~h}$ & $15 \mathrm{~h}$ \\
\hline Historiografia e o mundo colonial & $90 \mathrm{~h}$ & $60 \mathrm{~h}$ & $15 \mathrm{~h}$ & $15 \mathrm{~h}$ \\
\hline A Expansão Europeia & $90 \mathrm{~h}$ & $60 \mathrm{~h}$ & $15 \mathrm{~h}$ & $15 \mathrm{~h}$ \\
\hline Das revoluções atlânticas ao mundo contemporâneo & $90 \mathrm{~h}$ & $60 \mathrm{~h}$ & $15 \mathrm{~h}$ & $15 \mathrm{~h}$ \\
\hline $\begin{array}{l}\text { O mundo após a Guerra Fria e questões do tempo } \\
\text { presente }\end{array}$ & $90 \mathrm{~h}$ & $60 \mathrm{~h}$ & $15 \mathrm{~h}$ & $15 \mathrm{~h}$ \\
\hline História e Historiografia da África & $90 \mathrm{~h}$ & $60 \mathrm{~h}$ & $15 \mathrm{~h}$ & $15 \mathrm{~h}$ \\
\hline História e Historiografia da América & $90 \mathrm{~h}$ & $60 \mathrm{~h}$ & $15 \mathrm{~h}$ & $15 \mathrm{~h}$ \\
\hline História e Historiografia da Ásia & $90 \mathrm{~h}$ & $60 \mathrm{~h}$ & $15 \mathrm{~h}$ & $15 \mathrm{~h}$ \\
\hline Laboratório de Ensino, Fontes e Métodos I & $90 \mathrm{~h}$ & $30 \mathrm{~h}$ & $15 \mathrm{~h}$ & $45 \mathrm{~h}$ \\
\hline Laboratório de Ensino, Fontes e Métodos II & $90 \mathrm{~h}$ & $30 \mathrm{~h}$ & $15 \mathrm{~h}$ & $45 \mathrm{~h}$ \\
\hline Laboratório de Ensino, Fontes e Métodos III & $90 \mathrm{~h}$ & $30 \mathrm{~h}$ & $15 \mathrm{~h}$ & $45 \mathrm{~h}$ \\
\hline Carga Horária Total - Núcleo de História & $1260 \mathrm{~h}$ & $750 \mathrm{~h}$ & $210 \mathrm{~h}$ & $300 \mathrm{~h}$ \\
\hline Atividades livres de extensão (projetos) & & & $130 \mathrm{~h}$ & \\
\hline TOTAL DE EXTENSÃO & & & $340 \mathrm{~h}$ & \\
\hline
\end{tabular}

Fonte: PPC do Curso de Licenciatura em História da UNILAB, 2018, p. 37

Em ambos, a ausência de conteúdos obrigatórios sobre história nacional, a ênfase em eixos temáticos continentais, numa perspectiva de equilíbrio entre Europa, África, Ásia e América são evidências da busca de uma formação não apenas descolonizada, mas, também, descolonizadora, pois objetiva formar professores que levem para as escolas de seus países um olhar crítico sobre a centralidade ocidental da história humana.

O debate em torno da obrigatoriedade ou não dos conteúdos relativos às histórias nacionais, não apenas do Brasil, como também dos demais países que compõe o corpo discente da UNILAB foi, sem dúvida, o mais difícil, tanto da elaboração do PPC original quanto em sua reforma. No primeiro momento, esta dificuldade tinha a sua origem na própria formação dos que compunham a comissão de elaboração, que, embora tenham estudado em diferentes instituiçôes, estudaram sob a égide de um currículo que privilegiava, quer no ensino, quer na pesquisa, temas relativos à História do Brasil. Durante a reforma de 2017, feita por um grupo maior de professores, em sua maioria ausentes na formulação original, esta tensão foi ainda potencializada pelas críticas de alguns estudantes, brasileiros e estrangeiros, que defendiam a importância central dos conteúdos de história nacional para sua formação acadêmica.

Nas duas versões do PPC, venceu a tese de que, diante da impossibilidade de trazer os conteúdos relativos à história nacional de todos os países para o rol de disciplinas obrigatórias, sem quase 
duplicar o tempo de formação e da importância de manter o currículo dentro de um perfil internacional, intercultural e descolonizador, esses conteúdos seriam tratados em disciplinas optativas.

Outro paradigma importante foi a compreensão de que, atualmente, diversas questóes pautam as pesquisas nas ciências sociais (a Sociologia e os Estudos Culturais, em particular), que têm realizado reflexóes epistemológicas na busca de contrapontos críticos para definiçóes clássicas de conceitos como individuo, sujeito, identidade, e temas de estudos como negros, populaçôes migrantes, relaçôes de contato entre grupos variados que ganham novas dimensóes quando analisados à luz das recentes abordagens interdisciplinares e dos estudos pós-coloniais. Autores como Raymond Williams, Edward P. Thompson, Charles Taylor, Edward Said, Paul Gilroy, Stuart Hall, Homi K. Bhabha, Gayatri C. Spivak, Fredrik Barth, entre outros, têm desenvolvido novas bases teóricas sobre a cultura e a sociedade, embalados pelas profundas mudanças iniciadas desde os acontecimentos de Maio de 1968 e a irrupção das lutas dos "novos movimentos sociais” ou "novos sujeitos coletivos" e suas novas demandas por igualdade, direitos, reconhecimento e respeito às diferenças.

Por fim, a formulação do PPC do Curso de Licenciatura em História da UNILAB também buscou compreender, adequar-se a, e comprometer-se com um conjunto de transformaçóes positivas pelas quais o país passava (e de certo modo ainda passa). Transformaçóes que promoveram importantes e necessários questionamentos de alguns dos seus princípios fundacionais na nação, impondo novos olhares, ou paradigmas, em direção ao passado, presente e futuro. Sobre o tabuleiro está o jogo de xadrez da renegociação e da (re)formulação de uma nova sociedade em termos conceituais e funcionais. E uma peça-chave está no significado e na ressignificação de conceitos centrais como desigualdade, diversidade, diferença, identidade, pluralidade cultural e, principalmente, mestiçagem e miscigenação.

O Brasil é uma nação multirracial, pluriétnica e pautada por uma grande diversidade cultural; por outro lado, temos sistemas ou instituições educacionais, currículos, programas de ensino, material didático, práticas pedagógicas e individuais que ainda sacralizam uma visão machista, monocultural e eurocêntrica da sociedade brasileira. Contudo, ambos os lados da moeda não são dicotômicos, mas relacionais.

Mudanças na legislação educacional, em especial as leis 10.639/2003 e 11.645/2008, avançaram na pauta da inclusão de conteúdos étnico-raciais ${ }^{2}$. As conquistas jurídicas, sem dúvida, são fatos importantes; mas, o outro passo é a efetiva implementação das políticas públicas. Pois, estas tratam diretamente de questóes presentes no mundo real e funcional - geralmente cumprindo demandas dos movimentos sociais -, e sobre o presente e o futuro da educação e da sociedade brasileira.

Tomando estes elementos como princípios norteadores, a perspectiva foi a de construir, para o curso de Licenciatura em História, um PPC que ofertasse uma formação em História capaz de contribuir ativa e positivamente, no Brasil e nos demais países parceiros da UNILAB, para descolonização do saber histórico e para a necessária resistência à base epistemológica que há tempos orienta uma formação de matriz eurocêntrica. Nesse sentido, buscamos seguir a orientação da filósofa Martha Nussbaum (2015, p. 6-7), para quem as habilidades desenvolvidas pelas humanidades estimulam a imaginação, o pensamento crítico, a capacidade de colocar-se no lugar do outro, uma educação abrangente que forme cidadãos democráticos e com capacidade de inovação e de tomar decisões levando em consideração a diversidade dos Outros, pessoas que sejam capazes de pensar claramente, analisar um problema e imaginar algo novo. Por isso, "[...] defende que os currículos educacionais devem ter por objetivo tornar visíveis os grupos que a maioria da sociedade ignora”. 


\section{A formação do professor}

Importa de início informar que a separação entre formação em História e formação docente obedece, neste artigo, a uma necessidade de evidenciar para quem o lê as diferenças de avanços e dificuldades que o currículo enfrenta nessas áreas, não sendo, de modo algum, resultado de uma visão dicotômica da formação do licenciado em História. Os professores que atuam no curso compartilham a perspectiva de que a formação deve ser a de um professor-historiador e não de um historiador que ensina, ou de um professor que sabe história. Nesse sentido, as duas versóes do PPC do curso propõem percursos formativos em que formação em História e formação pedagógica devem ser conduzidas de modo dialógico e interligado.

No Brasil, como todos já sabem, temos duas modalidades de cursos de graduação, o bacharelado e a licenciatura. A primeira destinada à formação para o exercício de ofícios do que se convencionou chamar de campo das "profissões liberais” e a segunda destinada à formação de professores, com foco maior na preparação de quadros para a Educação Básica, nos níveis Fundamental e Médio.

Essas duas modalidades são reguladas por legislação federal, que normatiza princípios e diretrizes gerais de cada uma delas, bem como aspectos específicos da formação de cada campo profissional.

Quando analisamos as normas gerais para o bacharelado e para a licenciatura, fica evidente para esta segunda modalidade que há uma normatização a um só tempo mais ampla e rigorosa. Uma rápida pesquisa na legislação para educação superior revela que há em vigor, hoje em dia, no país, quatro vezes mais resoluções e pareceres do Conselho Nacional de Educação regulando forma e execução dos cursos de licenciatura, do que dos cursos de bacharelado. Ou seja, a formação de professores, no Brasil, tem uma maior ingerência normativa do Estado do que as demais áreas da educação superior. Este corpus normativo é defendido pelos membros do Conselho Nacional de Educação e da Secretaria de Ensino Superior do Ministério da Educação como uma necessidade garantidora de um mínimo de padrão nacional para a formação dos professores, bem como de aproximação da formação universitária com o universo escolar, especialmente com os sistemas públicos da Educação Básica.

Formulada com o objetivo de estabelecer um modelo formativo nacional para professores, a partir de um modelo ideal concebido pelo Estado, esta legislação estabelece conteúdos e carga horária imperativas com a intensão de aproximar a experiência da formação acadêmica da realidade escolar brasileira. Esta perspectiva é plenamente compreensível e necessária, para que tenhamos de fato a superação do enorme fosso que por décadas separou a formação universitária do campo escolar. No entanto, ela se torna um obstáculo, com grande poder de limitação, quando o objetivo de um curso é formar profissionais para atuar, também, fora do Brasil.

Em seu artigo primeiro, no parágrafo 2o, e no artigo quinto, a Resolução 02/2015 do Conselho Nacional de Educação, documento basilar do disciplinamento das licenciaturas no Brasil, estabelece que:

$\S 2$ 을 As instituições de ensino superior devem conceber a formação inicial e continuada dos profissionais do magistério da educação básica na perspectiva do atendimento às políticas públicas de educação, às Diretrizes Curriculares Nacionais [...]

Art. 5o A formação de profissionais do magistério deve assegurar a base comum nacional, pautada pela concepção de educação como processo emancipatório e permanente, bem como pelo reconhecimento da especificidade do trabalho docente, que conduz à práxis como expressão 
da articulação entre teoria e prática e à exigência de que se leve em conta a realidade dos ambientes das instituições educativas da educação básica e da profissão. (BRASIL, 2015, p. 2)

Desse modo, para ter o seu Projeto Pedagógico Curricular aprovado no processo de reconhecimento do Ministério da Educação e ser autorizado a funcionar, um curso de licenciatura deve, obrigatoriamente, alinhá-lo às normas e diretrizes que configuram a Educação Básica brasileira. Somando isso à exigência do ensino de Língua Brasileira de Sinais (Libras), estabelecida pelo Decreto Presidencial no 5.626/2005, temos um grande volume de conteúdos estritamente vinculados à realidade educacional brasileira, que acabam por preencher cerca de $15 \%$ da carga horária do curso. ${ }^{3}$

A exigência de um mínimo de 400 horas de Prática como Componente Curricular, de um mínimo de 400 horas de Estágio Supervisionado, definidas pelo artigo treze da Resolução 02/2015 do Conselho Nacional de Educação, juntamente com as 200 horas de atividades complementares, exigidas pela Resolução 02/2002 do mesmo Conselho Nacional de Educação, ocupam outros 25\% da carga horária do curso. Para além destas normatizações específicas para os cursos de formação de professores, há ainda as exigências, comuns a todos os cursos de graduação no Brasil, de que 10\% da carga horária seja preenchida por atividades de extensão, definida pelo Plano Nacional da Educação, Lei no $13.005 / 2014$. $^{4}$

Em conjunto, estas normas terminam por definir, de modo imperativo, algo próximo a $45 \%$ da carga horária do curso, deixando uma margem de autonomia bastante restrita para a livre escolha dos colegiados. No caso específico da Licenciatura em História da UNILAB, esses conteúdos, como demonstra o quadro a seguir, ocupam um total de 1.240 horas.

Quadro 3 - Distribuição de carga horária PPC atual

\begin{tabular}{|l|l|c|c|}
\hline \multirow{2}{*}{ CICLO } & NÚCLEO & CH & \multicolumn{2}{|c|}{ PERCENTUAL } \\
\hline \multirow{2}{*}{ Primeiro } & Núcleo Obrigatório de Conhecimento em Humanidadess & $240 \mathrm{~h}$ & \\
\cline { 2 - 5 } & Núcleo Obrigatório Comum da Unilabs & $240 \mathrm{~h}$ & \\
\hline \multirow{3}{*}{ Segundo } & Núcleo Específico da Área da Histórias & $1250 \mathrm{~h}$ & \\
\cline { 2 - 5 } & Núcleo da Área de Educação & $300 \mathrm{~h}$ & \\
\cline { 2 - 5 } & Estágio Supervisionado & $405 \mathrm{~h}$ & \\
\cline { 2 - 5 } & Núcleo Optativo & $450 \mathrm{~h}$ & \\
\cline { 2 - 5 } & Núcleo Eletivo & $120 \mathrm{~h}$ & \\
\hline Atividades Complementares & $200 \mathrm{~h}$ & \\
\hline CARGA HORÁRIA TOTAL & $3.345 \mathbf{h}$ & $\mathbf{1 0 0 \%}$ & $\mathbf{1 0 0 \%}$ \\
\hline Atividades de Extensão & $\mathbf{3 4 0 h}$ & $\mathbf{1 0 \%}$ & $\mathbf{1 0 \%}$ \\
\hline
\end{tabular}

Fonte: PPC do Curso de Licenciatura em História da UNILAB, 2017, p. 61

Diante destas amarras normativas sobre conteúdos e carga horária, o curso teve que assumir, no que diz respeito à área de formação docente, um perfil mais fechado e orientado para a realidade brasileira, diferentemente do que se vê na área da formação histórica. Conteúdos relativos à legislação, aos conteúdos e às práticas de funcionamento da educação escolar nos países parceiros tiveram que ser deslocados para disciplinas optativas, que se ocupam de conteúdos específicos de suas histórias nacionais. 
Quadro 4 - Quadro de disciplinas optativas de história nacional PPC atual

\begin{tabular}{|l|c|}
\hline Disciplinas Optativas & Carga Horária \\
\hline Tópicos em História de Timor-Leste & $75 \mathrm{~h}$ \\
\hline Tópicos em História de Cabo Verde & $75 \mathrm{~h}$ \\
\hline Tópicos em História de São Tomé e Príncipe & $75 \mathrm{~h}$ \\
\hline Tópicos em História da Guiné-Bissau & $75 \mathrm{~h}$ \\
\hline Tópicos em História de Angola & $75 \mathrm{~h}$ \\
\hline Tópicos em História de Moçambique & $75 \mathrm{~h}$ \\
\hline
\end{tabular}

Fonte: PPC do Curso de Licenciatura em História da UNILAB, 2017, p. 60

Esta situação, compreendo, configura uma distorção que privilegia o modelo educacional brasileiro em detrimento daqueles dos países africanos de língua portuguesa, rompendo com o paradigma de internacionalidade e multiplicidade sociocultural que fundamenta a existência da UNILAB e deve servir de paradigma para a formatação das formaçóes que ela oferece.

Este quadro se agrava ainda mais quando olhamos o perfil formativo e de atuação profissional dos docentes do curso. Perfazemos hoje em dia um total de dezessete professores, todos com formação de doutorado, destes, apenas dois possuem, em sua formação, experiência ligada ao estudo de temáticas africanas, nenhum realizou estudos específicos sobre educação nos países africanos de língua portuguesa.

$\mathrm{Na}$ área de Teoria e Metodologia do Ensino e da Pesquisa em História, que é a responsável pela coordenação e oferta das disciplinas de formação docente do curso, todos os professores têm seus estudos formativos (monografias, dissertações e teses) e atuação atual em pesquisa voltados para temas de História do Brasil, ou educação brasileira. Em consequência da composição desse quadro docente, as disciplinas optativas que contemplam, em parte, temas relativos à educação nos países parceiros, na prática, não são objeto de oferta regular. Apenas a disciplina de História da Guiné Bissau já teve sua oferta concretizada, por duas vezes, sem, porém, contemplar o conteúdo referente à história e à legislação da educação, devido ao pouco conhecimento do tema pela ministrante, que tem seu foco de estudo voltado para o campo da história política, e, também, à falta de bibliografia e de referências documentais sobre o tema.

A falta de informações sobre o sistema educacional em geral e sobre o ensino de História em particular nos países parceiros da UNILAB é um déficit que temos tido muita dificuldade de suprir. Existem poucos trabalhos acadêmicos disponíveis, sejam artigos ou livros, que abordem os sistemas educativos de Angola, Cabo Verde, Guiné Bissau, Moçambique e São Tomé e Príncipe, nenhum, que tenhamos localizado, que se debruce especificamente sobre o ensino de História. A maior parte do que conseguimos reunir diz respeito a análises feitas por órgãos da ONU, que se propõem a traçar um panorama estatístico sobre os índices de escolarização.

As páginas oficiais dos estados, mais especificamente dos órgãos responsáveis pela gestão da educação, contrariamente ao que ocorre aqui no Brasil, não disponibilizam versões digitais de seus instrumentos normativos. Mesmo com o apoio da Pró-Reitoria de Assuntos Institucionais da UNILAB, que tem como uma de suas atribuições intermediar diálogos e parcerias com órgãos governamentais e instituiçôes educacionais dos países parceiros, não temos tido sucesso em obter cópias da legislação vigente, para que possamos estudar e discutir junto com os licenciandos. 
No processo de montagem do Curso de Licenciatura em História, havia uma orientação, presente na primeira versão do Estatuto da UNILAB, de que os estudantes estrangeiros poderiam cumprir o estágio supervisionado em seus países de origem. Essa perspectiva nos animou bastante, pois enxergamos nisso a possibilidade de construir uma ponte sólida e efetiva com os sistemas de educação básica dos países parceiros, além de propiciar aos estudantes uma aproximação real com o campo de trabalho em que atuarão após a conclusão do curso e o retorno para casa. Esta possibilidade, contudo, foi frustrada pela alegação do Ministério da Educação brasileiro de que esta ação demandaria uma logística muito dispendiosa aos cofres públicos, além de impossibilitar a correta e efetiva fiscalização das atividades de estágio.

Em decorrência de todos estes entraves acadêmicos, normativos e burocráticos, o Curso de Licenciatura em História da UNILAB formula e pratica a formação docente de seus estudantes fundamentadas no e voltadas ao modelo e na experiência educacional brasileira, o que tem motivado diversos e coerentes questionamentos dos discentes estrangeiros, bem como deixado o seu corpo docente apreensivo sobre a qualidade da formação oferecida e o efetivo preparo do egresso para ingressar na vida profissional fora do Brasil.

Esta situação tem sido a causa maior da pouca afluência de estudantes estrangeiros para o curso. Desde que começou a funcionar efetivamente, no ano de 2015, o curso teve o ingresso de 211 estudantes, dos quais apenas vinte são estrangeiros ${ }^{1}$, (dezenove guineenses e um moçambicano), um percentual inferior a $10 \%$, quando a média geral da universidade é $32 \%$ de estudantes estrangeiros.

\section{Considerações finais}

Em seu excelente artigo publicado na Revista Internacional de Formação de Professores, Ana Maria Iorio Dias observa que:

[...] o mundo atual apresenta novos desafios e faz novas exigências à escola e à formação de professores. Transformaçóes na organização familiar, no mundo trabalho, na realidade social e cultural cotidiana trazidas pelo desenvolvimento tecnológico; as questóes ambientais; o desemprego e a exclusão social ocasionados pelo modelo econômico neoliberal; a violência; a corrupção; o terrorismo e o imperialismo; a globalização; e o multiculturalismo são algumas das peculiaridades que marcam o nosso tempo e das quais professores dos diferentes níveis de ensino não podem se omitir. Docentes são educadores, formadores, não há como formar, educar, sem referência às problemáticas contemporâneas. $\mathrm{O}$ atendimento a essas exigências passa pela formação adequada dos professores. (DIAS, 2016, p. 109)

Assim como o Brasil, os países africanos de língua oficial portuguesa (lusófonos) têm como um de seus grandes desafios a construção de uma educação que prepare crianças e jovens para o exercício pleno da cidadania. Isso passa, necessariamente, por um ensino de história que valorize e aponte os caminhos para uma resistência ao domínio narrativo e epistemológico eurocêntrico.

Alcançar esse objetivo passa pela atenção à diversidade e à complexidade a que, reporta-se Dias, deve estar presente na formação dos professores de História, mais do que isso, precisa se constituir em eixo central dos currículos dos cursos, sob pena de seguirmos franqueando uma formação desconectada da realidade dos estudantes e do campo escolar com que eles vão lidar depois de formados. 
O currículo escolar (ou universitário) é definido pelo psicólogo e educador espanhol César Coll Salvador (2009) como sendo um projeto, ou seja, como um instrumento que orienta uma execução. E, como todo projeto, um currículo não é algo pronto e acabado, ele se caracteriza como um devir, no sentido que o filósofo grego Heráclito deu à palavra, ou seja, um tornar-se constante.

Nessa perspectiva, o currículo só tem razão de existir em diálogo constante com a realidade em que está inserido. Todo currículo é uma construção política que deve pôr em diálogo as normas reguladoras da educação e os sujeitos que experienciam a educação no dia a dia. Partindo dessa premissa, é legítimo afirmar que um currículo é tanto mais eficiente quanto for a sua capacidade de incluir e trabalhar com as muitas diferenças sociais, culturais e econômicas presentes em cada configuração educativa específica.

Como bem nos adverte Antonia Terra Calazans Fernandes:

Formar professores de História é um desafio que envolve muita responsabilidade. Os temas escolhidos para o estudo, a bibliografia, os enfoques fazem diferença na formação do futuro educador. (FERNANDES, 2017, p. 1)

Em grande medida, o Projeto Pedagógico Curricular do Curso de Licenciatura em História da UNILAB contempla todas essas premissas, conseguindo estabelecer um diálogo eficiente com os anseios e as necessidades de seu tão plural corpo discente e pô-los em diálogo com as regulaçóes da universidade, orientada para a parceria Brasil-África Lusófona, e com uma parte expressiva da legislação brasileira para a educação superior, modalidade licenciatura, em especial as leis 10.639/2003 e 11.645/2008. Nisso ele se constitui em instrumento de uma formação de professores na e pela descolonização da educação nas ex-colônias portuguesas na América e na África, que possam contribuir ativamente na construção de propostas educacionais de resistência à hegemonia do Norte.

Por outro lado, o projeto se contradiz ou ao menos empobrece sua orientação plural e inclusiva quando orienta toda a formação pedagógica dos estudantes (teórica e prática) sob alinhamento exclusivo com o que regula e pratica a educação brasileira. Nesse sentido, a reponsabilidade que pesa sobre o curso, ao se propor a formar professores de história para atuar em seis países, de dois continentes diferentes, não é cumprida em sua integralidade.

Esta fragilidade do curso é algo claro e consciente para todos os seus docentes, bem como o são as dificuldades em superá-la, diante da multiplicidade de causas e origens que tem. A constatação da complexidade da situação, contudo, não é percebida pelo colegiado de docentes do curso como insuperável. Conseguir trazer para o espectro formativo do curso a diversidade dos modelos e das práticas educacionais de todos os países de onde recebe estudantes e é compreendida como uma necessidade, além de perseguida como uma meta que importa muito ser alcançada. Não há ainda clareza sobre os caminhos que conduzirão a esse reordenamento da formação pedagógica, mas há um esforço sincero de refletir sobre isso, este artigo é parte dele, pois poucas coisas são tão imperativas ao ofício do historiador do que transformar os problemas que o mundo lhe apresenta em problemática de pesquisa.

Pôr em prática uma proposta de formação de professores-historiadores plural, descolonizada e internacional é um desafio inédito no Brasil e, por vezes, parece impossível de executar, mas apenas parece. Há ainda um longo caminho a percorrer, muito a aprender e a construir, em especial na efetivação de um diálogo efetivo e eficiente com o campo da educação básica nos países parceiros, no entanto, a perspectiva é de que temos um ponto de partida sólido e muito ânimo para criar o que ainda não existe e modificar o que precisa de adequações e rearranjos. 


\section{Referências}

BRASIL. Resolução $n^{\circ}$ 2/2015. Conselho Nacional de Educação. Conselho Pleno, Ministério da Educação, Poder Executivo, Brasília.

BRASIL. Decreto Lei $n^{\circ}$ 5.626, de 22 de dezembro de 2002. Diário Oficial da União, Poder Executivo, Brasília.

BRASIL. Lei 10.639/2003, de 9 de janeiro de 2003. Altera a Lei n 9. 394, de 20 de dezembro de 1996. Diário Oficial da União, Poder Executivo, Brasília.

BRASIL. Lei 11.645/08 de 10 de março de 2008. Diário Oficial da União, Poder Executivo, Brasília.

BRASIL. Lei n. ${ }^{\circ}$ 13.005/2014, de 25 de junho de 2014. Diário Oficial da União, Poder Executivo, Brasília.

CONTEL, Fabio Betioli; LIMA, Manolita Correia. Internacionalização da educação superior. São Paulo: Alameda Editorial, 2011.

DIAS, Ana M. Iorio. Passado e presente na formação de professores: por entre perspectivas históricas, legais e políticas. Revista Internacional de Formação de Professores. Itapetininga v. 1, n. 2, 2016.

DUSSEL, Enrique. Ética da libertação: na idade da globalização e da exclusão. Petrópolis: Vozes, 2000.

FERNANDES, Antonia Terra de Calazans. Desafios na Formação de Professores de História. São Paulo. Revista Graduação USP, v. 2, n. 2, jun. 2017.

FERREIRA, Marieta de Morais; SILVA, Norma Lúcia da. Expansão do ensino superior de História em direção ao interior: a formação do campo de Goiás. História Revista. Goiânia, v. 21, n. 1, jan./abr. 2016.

GILROY, Paul. O Atlântico Negro. Modernidade e dupla consciência. São Paulo; Rio de Janeiro: 34: Universidade Cândido Mendes - Centro de Estudos Afro-Asiáticos, 2001.

GOMES, N. G.; LERCHE, Sofia. Construindo uma ponte Brasil-África: a Universidade da Integração Internacional da Lusofonia Afro-Brasileira (UNILAB). Revista Lusófona de Educação. Lisboa, n 24, 2013.

HALL, Stuart. A identidade e a cultura na pós-modernidade. 11. ed. Rio de Janeiro: DP\&A, 2006.

NUNES, João Arriscado. O resgate da epistemologia. In: SANTOS, Boaventura de Sousa; MENESES, Maria Paula. Epistemologias do sul. São Paulo: Cortez, 2010.

NUSSBAUM, Martha. Sem fins lucrativos. Porque a democracia precisa das humanidades. São Paulo: Martins Fontes, 2015.

SAID, Edward W. Cultura e Imperialismo. São Paulo: Companhia das Letras, 2011.

SALVADOR, César Coll. Psicología y Currículum: una aproximación psicopedagógica a la elaboración del currículum escolar. Barcelona: Ediciones Paidós Ibérica, 2009.

SILVA, Tomaz Tadeu da. Documentos de identidade: uma introdução às teorias do currículo. Belo Horizonte: Autêntica, 1999.

SPIVAK, Gayatri C. Pode o subalterno falar? Belo Horizonte: EdUFMG, 1985.

TAYLOR, Charles. El multiculturalismo y la política del reconocimiento. Cidade do México: Fondo de Cultura Económica, 1993.

THOMPSON, Edward P. Costumes em Comum. Estudos sobre a cultura popular tradicional. São Paulo: Companhia das Letras, 1998.

UNIVERSIDADE DA INTEGRAÇÃO INTERNACIONAL DA LUSOFONIA AFRO-BRASILEIRA. Resolução $n^{\circ}$ 15/2014. Conselho Superior Pro-Tempore, Redenção.

UNIVERSIDADE DA INTEGRAÇÃO INTERNACIONAL DA LUSOFONIA AFRO-BRASILEIRA. Resolução $n^{\circ}$ 43/2018. Conselho Superior Pro-Tempore, Redenção.

WILLIAMS, Raymond. Cultura. Rio de Janeiro: Zahar, 1991. 


\section{Notas}

${ }^{1} O$ atual PPC do curso, aprovado pela Resolução n 43/2018 do Conselho Universitário está disponível em: http://www. unilab.edu.br/wp-content/uploads/2019/07/PPC.-V8.-Hist\%C3\%B3ria.-Semestral.03.-Abril.-2019-1.pdf. Acesso em: 3 fev. 2020.

${ }^{2}$ A Lei10.639/2003 está disponível em: http://www.planalto.gov.br/ccivil_03/leis/2003/l10.639.htm. Acesso em: 27 dez. 2019. A Lei 11.645/2008 está disponivel em: http://www.planalto.gov.br/ccivil_03/_Ato2007-2010/2008/Lei/L11645. htm. Acesso em: 3 fev. 2020.

${ }^{3}$ O Decreto Presidencial n 5.626/2005 está disponível em: http://www.planalto.gov.br/ccivil_03/_Ato2004-2006/2005/ Decreto/D5626.htm. Acesso em: 3 fev. 2020.

${ }^{4}$ O Plano Nacional da Educação, Lei n 13.005/2014 está disponível em: http://pne.mec.gov.br/18-planos-subnacionaisde-educacao/543-plano-nacional-de-educacao-lei-n-13-005-2014. Acesso em: 4 fev. 2020.

${ }^{5}$ Nenhum destes estudantes estrangeiros concluiu o curso até o momento. Um deles, guineense, está no último período do curso, devendo colar grau em novembro de 2018. Há hoje em dia quatro estudantes guineenses cursando o terço final do curso (no qual estão alocadas as disciplinas de Estágio Supervisionado), dos quais, três participam do Programa de Residência Pedagógica da CAPES.

Recebido em: 11/06/2019

Aprovado em: 05/01/2020 